\title{
Concepções e Estratégias Pedagógicas Inovadoras: um Modelo de Ensino na Escola Plena Arena da Educação em Mato Grosso
}

\section{Innovative Pedagogical Conceptions and Strategies: a Teaching Model at Full-Time School Arena da Educação in Mato Grosso}

\author{
Flávio Marcelo Bueno de Castro $;$; Edenar Souza Monteiro*a \\ ${ }^{a}$ Universidade de Cuiabá, Programa Pós-Graduação em Ensino. MT, Brasil. \\ *E-mail: edenar.monteiro@kroton.com.br
}

\begin{abstract}
Resumo
Trata-se de uma pesquisa em recorte de uma dissertação de mestrado, cujo objetivo é conhecer como funciona o modelo de ensino "Escola Plena" ofertado na Escola Estadual Gov. José Fragelli contemplando as estratégias pedagógicas, que os docentes adotam para articular os saberes da Base Nacional Comum Curricular e das modalidades esportivas. A Escola Plena é uma instituição de ensino que tem como diferencial atender alunos do Ensino Fundamental e Médio em Tempo Integral e tem se destacado, positivamente, dentro do modelo de Ensino Integral no Estado de Mato Grosso. O projeto para criação da escola ocorreu via programa Pró-Escolas/Esportes e Lazer, sendo criado e desenvolvido pela Secretaria de Educação do Estado em 2017 com objetivos estratégicos do Governo vinculados à Educação. A pesquisa é qualitativa e a metodologia utilizada é a Análise de Conteúdo. Os instrumentos para a coleta foram realizados por meio de análise documental e entrevistas semiestruturadas com os participantes da pesquisa, que são docentes da referida escola. Diante dos resultados se percebeu que o modelo de ensino da referida escola exige muita dedicação e empenho por se tratar de um contexto em que o aluno e os professores se dedicam integralmente. As práticas pedagógicas adotadas pelos docentes contribuem para a qualidade na educação e para formação integral do estudante e a construção do seu projeto de vida.
\end{abstract}

Palavras-chave: Fazer Docente. Componentes Curriculares. Ensino-Aprendizagem.

\begin{abstract}
It is a research, part of a master's dissertation, whose objective is to know how the "Full-time School " teaching model offered at Escola Estadual Gov. José Fragelli works, contemplating the pedagogical strategies that the teachers adopt to articulate the knowledge of the Common National Core Curriculum and sports modalities. Full-time School is a teaching institution whose differential is to serve students from elementary and high school full time and has stood out positively within the model of full-time education in the State of Mato Grosso. The project for the creation of the school took place via the Pro-Schools / Sports and Leisure program, being created and developed by the State Department of Education in 2017 with strategic government objectives linked to education. The research is qualitative and the methodology used is Content Analysis. The instruments for the collection were carried out by means of documentary analysis and semi-structured interviews with the research participants, who are teachers at that school. Due to the results, it was noticed that the teaching model of that school requires a lot of dedication and commitment because it is a context in which the student and teachers are fully dedicated. The pedagogical practices adopted by the teachers contribute to the quality of education and to the whole student's formation and the construction of his or her life project.
\end{abstract}

Keywords: Teaching. Curricular Components. Teaching-Learning.

\section{Introdução}

A Escola Plena ${ }^{1}$ é uma instituição de ensino que tem como diferencial atender estudantes do Ensino Fundamental e Médio em Tempo Integral e tem se destacado, positivamente, dentro do modelo de Ensino Integral no Estado de Mato Grosso. Seu objetivo é garantir que os estudantes possam ter acesso à uma educação integral e de excelência, mesmo na rede pública, além de garantir aos profissionais uma segurança para atuar nessa modalidade de ensino. Esse modelo de educação permite um tempo maior de permanência do estudante na escola com um currículo mais diversificado com a apropriação de saberes da comunidade que envolve diretamente a escola. Isso cria subsídios para que o educando se integre melhor com a sociedade utilizando o que é o mais importante, que é o capital intelectual. Este modelo de Escola se vale de pesquisas para saber quem são os sujeitos que compõem seu grupo para dar-lhes condições para a formação de estudantes autônomos, solidários e competentes.

A Escola Plena de vocação esportiva ${ }^{2}$ permite ao estudante, por meio das práticas esportivas, o desenvolvimento de

1 Disponível em: http://www.mt.gov.br/-/8370167-governo-sanciona-lei-que-institui-as-escolas-plenas-em-mato-grosso

$2 \mathrm{O}$ termo "vocação esportiva" consta no documento que fundamenta a criação da escola e tem todo o seu projeto pedagógico descrito no Decreto $\mathrm{n}^{\circ}$ 891/2017, constante no Diário Oficial do Estado de Mato Grosso de 14 de novembro de 2017. 
habilidades relacionadas com a integração em grupo, criação de estratégias, de motivação, de criatividade, de comunicação, de compreensão dos limites seus e dos outros, de interpretação de situações, de convivência, de saber ganhar e perder, de respeito ao próximo, de aceitação de limites, de autonomia, de liderança e cooperação. Reconhecendo erros e aprendendo a corrigi-los em competições recreativas e/ou competitivas e sadias.

A estrutura pedagógica da escola com vocação esportiva está organizada em componentes curriculares da Base Nacional Comum Curricular por Área de Conhecimento e por temáticas na parte Diversificada do currículo. Essa organização curricular deve promover a articulação e a integração de todos os componentes curriculares, pois não visa apenas excelência no esporte, mas também a acadêmica.

A Parte Diversificada denominada Práticas Esportivas, com carga horária significativa do currículo, deve contemplar a formação e o desenvolvimento esportivo, contribuir para o desenvolvimento integral do cidadão, que aprende a conhecer, a fazer, a conviver e a ser. Para tanto, é necessário serem repensados os objetivos do "esporte na escola" para o "esporte da escola", constituído por característica ímpar, própria das escolas de vocação esportiva.

O espaço educativo da escola propicia aos estudantes o contato e a vivência nas modalidades coletivas de Futsal e Basquete e nas individuais: Vôlei de praia, Luta Olímpica, Ginástica Rítmica, Judô, Tênis de mesa, Xadrez, Atletismo e Natação, contemplando as dez modalidades do currículo.

Trata-se de uma pesquisa cujo objetivo é conhecer como funciona o modelo de ensino "Escola Plena" ofertado na Escola Estadual Gov. José Fragelli contemplando as estratégias pedagógicas de mediação, que os docentes adotam para articular os saberes da Base Nacional Comum Curricular e das modalidades esportivas. A pesquisa é qualitativa (MINAYO, 2018) e a metodologia utilizada é a Análise de Conteúdo (BARDIN, 2016); (BAUER; GASKELL, 2003). Os instrumentos para a coleta de dados amparados por Chizzotti (2003) estão sendo realizados por meio de análise documental e entrevistas semiestruturadas com os participantes da pesquisa, que são docentes da referida escola.

\section{Material e métodos}

O trabalho consiste em uma pesquisa com abordagem qualitativa (MINAYO, 2018) e o método utilizado foi o estudo de caso (CHIZZOTTI, 2003). Para Minayo (2018), “a pesquisa qualitativa responde a questões muito particulares. Ela se ocupa, dentro das Ciências Sociais, com o universo dos significados, dos motivos, das aspirações, das crenças, dos valores e das atitudes".

Segundo Chizotti (2003, p.49), o estudo de caso:

é uma caracterização abrangente para designar uma diversidade de pesquisas que coletam e registram dados de um caso particular ou de vários casos, a fim de organizar um relatório ordenado e crítico de uma experiência, ou avaliá-la analiticamente, objetivando tomar decisões a seu respeito ou propor uma ação transformadora.

Os procedimentos adotados para a coleta de dados foram realizados por meio de pesquisa documental de documentos públicos que constam nos sites do Governo para embasamento teórico da pesquisa e entrevistas semiestruturadas com os participantes da pesquisa - gestores e docentes da Escola Plena Governador José Fragelli.

A princípio foram selecionados dois professores de cada área do conhecimento e dois das modalidades esportivas. Cabe lembrar que neste modelo de escola existem quatro áreas, sendo essas: Linguagens e suas tecnologias, Ciências Humanas, Ciências da Natureza e Matemática e Modalidades Esportivas, totalizando oito professores e três gestores como participantes da pesquisa.

O projeto foi aprovado pelo parecer 3.441 .852 de 05 de julho de 2019 pelo Comitê de Ética em Pesquisa em Seres Humanos da Universidade de Cuiabá, que é regulamentado pelo CONEP. O questionamento relacionado à pesquisa é: como funciona o modelo de ensino "Escola Plena" que atende estudantes da Escola Estadual Gov. José Fragelli e como são realizadas as estratégias pedagógicas.

As entrevistas foram gravadas oralmente por meio de telefones celulares e foram transcritas seguindo fielmente o que foi falado ao longo da entrevista. A maioria das entrevistas foi realizada em uma sala de aula, na escola investigada, de modo presencial e duas remotamente via aplicativo WhatsApp. Os questionamentos aos professores e gestores compreendem desde as metodologias aplicadas com os estudantes até as suas experiências e desafios encontrados ao longo do percurso trabalhado na escola.

A interpretação dos dados foi realizada por meio da análise do conteúdo, que tem como referência principal Bardin (2016) e Bauer e Gaskell (2003).

\section{Resultados e Discussão}

Não há dúvidas de que a referida Escola é importante para a melhora da qualidade do aprendizado do educando e que vem se fazendo cada vez mais presente na atual sociedade mato-grossense. Atualmente, são 39 unidades escolares e a cada ano que passa vem aumentando o número de escolas que passaram a ofertar o Ensino Integral, baseado na Lei $\mathrm{n}^{\circ}$ 10.622, a qual foi instituída no Estado de Mato Grosso no dia 24 de outubro de 2017, conhecida como a "Lei das Escolas Plenas".

Gonçalves (2006, p.3) já afirmava que “o conceito mais tradicional encontrado para a definição de educação integral é aquele que considera o sujeito em sua condição multidimensional, não apenas na sua dimensão cognitiva, como também na compreensão de um sujeito que é sujeito corpóreo, tem afetos e está inserido em um contexto de relações." Isso vale dizer que a compreensão de um sujeito que deve ser considerado em sua dimensão biopsicossocial. 
Acrescenta-se, ainda, que o sujeito multidimensional é um sujeito desejante, o que significa considerar que, além da satisfação de suas necessidades básicas, ele tem demandas simbólicas, busca satisfação em suas diversas formulações de realização, tanto nas atividades de criação quanto na obtenção de prazer nas mais variadas formas.

Xavier (2012) reforça que o que se caracteriza como uma Educação Integral é o reconhecimento da necessidade de ampliar e qualificar o tempo escolar, superando o caráter parcial e limitado que as poucas horas diárias proporcionam, em estreita associação com o reconhecimento das múltiplas dimensões que caracterizam os seres humanos.

Foi nesse sentido que o Governo do Estado de Mato Grosso, em 2017, concretizou a criação da Escola Estadual Governador José Fragelli, conhecida como "Arena da Educação". É uma escola com sede no interior da Arena Pantanal e que faz o uso de todo o complexo esportivo, como o Ginásio Aecim Tocantins, a piscina olímpica e as quadras de vôlei de praia. Essa é a única escola no país a ter como perfil ser um Estádio-escola. A identidade da escola é descrita como vocacionada à prática esportiva. Os professores são orientados a realizarem os seus planejamentos e projetos interligando os conteúdos da BNCC (Base Nacional Comum Curricular) com as modalidades esportivas oferecidas pela escola.

Para desenvolver a pesquisa estão sendo analisados os documentos:

- PPP - Projeto Político Pedagógico;

- Projeto Pedagógico das Escolas Plenas no Estado de Mato Grosso; e

- Lei Estadual de criação das Escolas Plenas.

A Escola conta com 240 alunos no ano de 2019 e sua oferta de ensino é o Fundamental e o Médio. A escola possui dez turmas, sendo três turmas do oitavo ano, três turmas do nono, duas turmas do primeiro ano, uma do segundo ano e uma do terceiro ano.

As aulas dos componentes curriculares da BNCC e alguns da parte Diversificada são realizadas dentro da escola no $2^{\circ}$ andar do setor Leste da Arena Pantanal e as dez modalidades esportivas são distribuídas pelo complexo da Arena Pantanal.

A escola atende em período integral com entrada dos alunos às $07: 00 \mathrm{~h}$ no período matutino e a saída é às $18: 30 \mathrm{~h}$ no período vespertino. Os alunos recebem três refeições diárias, sendo um lanche no período matutino, um almoço e um lanche no período vespertino.

A estrutura da Escola compreende um diretor, um coordenador pedagógico, quatro orientadores de áreas, que são da área de Humanas, Linguagem, Exatas e Prática Esportiva, sendo doze professores de modalidades e vinte e cinco professores da Base Comum, três secretários administrativos, uma bibliotecária e dez pessoas na área do Apoio.

De acordo com Mato Grosso (2017) consta no:

Art. $2^{\circ}$ - O Projeto Escola Plena possui as seguintes diretrizes:

I - Desenvolver ações inovadoras relativas ao currículo e

à gestão escolar, direcionadas à melhoria da qualidade do ensino na rede estadual de educação;
II - Sistematizar, implementar e difundir o modelo de educação integral na rede estadual de ensino;

III - Oferecer atividades que influenciem práticas inovadoras ao processo de ensino-aprendizagem, a fim de melhorar a sua qualidade;

IV - Estimular a participação da comunidade escolar na elaboração do projeto político-pedagógico da escola;

$\mathrm{V}$ - Ampliar a jornada escolar, a fim de promover a formação integral e integrada do estudante; e

VI - Integrar o ensino médio à educação profissional.

As escolas plenas possuem um modelo pedagógico diferenciado que tem como base o projeto de vida dos alunos, tal projeto funciona nessas escolas como modelo pedagógico e existe também como disciplina curricular da base diversificada. A ideia central aqui é que toda a escola gire em torno do projeto de vida dos alunos, pois todos os funcionários possuem mecanismos de acesso aos projetos, assim, o professor de Matemática pode desenvolver aulas que mostrem para os alunos como o conteúdo pode auxiliar no êxito de seus projetos de vida, sendo que o mesmo acontece com as demais disciplinas, tanto da Base Comum quanto da diversificada.

De acordo com o ICE (2015), o Projeto de Vida reside no "coração" do projeto escolar. Esse é o seu eixo, sua centralidade e sua razão de existir. É fruto do foco e da conjugação de todos os esforços da equipe escolar. É nesse que o currículo e a prática pedagógica realizam o seu sentido, no aspecto formativo e contributivo, na vida do jovem ao final da Educação Básica.

As disciplinas são divididas em Base Comum e Base Diversificada, sendo a Base Comum: Português, Matemática, Inglês, Geografia, História, Ciências, Arte, Ensino Religioso, Filosofia, Sociologia, Biologia, Física e Química. A Base Diversificada tem o Protagonismo Estudantil, Projeto de Vida, Iniciação Científica, Prática Experimental, Estudo Aplicado de Matemática, Estudo Aplicado de Português, Estudo Orientado, Avaliação Semanal e Eletivas.

É preciso ressaltar que o modelo pedagógico da Escola Plena abre espaço para duas práticas que auxiliam no desenvolvimento do protagonismo dos estudantes, que são os acolhimentos e os clubes de interesse. Os acolhimentos consistem em iniciativas de recepção dos alunos na escola e podem ser realizados por funcionários ou mesmo alunos, proporcionando um início do dia agradável a todos.

Os clubes de interesse são tempos dedicados aos estudantes para que desenvolvam atividades como clube de leitura, xadrez, jogos, entre outros. Normalmente, ocorre após o almoço ou após as aulas, sendo organizado pelos próprios estudantes e pode possuir auxílio inicial de um professor. Nesse momento, eles desenvolvem seu protagonismo organizando e realizando atividades de seu interesse de maneira ordenada. Os clubes possuem presidentes que se reúnem sempre que possível com o diretor da escola para tratar de assuntos relevantes a seus interesses.

A Prática Esportiva na Escola Estadual Governador José Fragelli segue como uma disciplina na parte diversificada, e 
tem como objetivo potencializar no aluno o desenvolvimento de uma prática esportiva durante o período escolar (EEGJF, 2019).

De todas as Escolas Plenas do Estado de Mato Grosso, a Escola Estadual Governador José Fragelli é a única que apresenta essa disciplina esportiva. No seu currículo do Ensino Fundamental e Médio os alunos têm duas aulas-horas de prática por dia, somando dez horas semanais. As modalidades ofertadas na escola são: Atletismo, Basquete, Futsal, Ginástica Rítmica, Judô, Luta Olímpica, Natação, Vôlei de praia, Tênis de mesa e Xadrez (EEGJF, 2019).

Para admissão na escola, os alunos participam no início do ano de uma seleção que tem como objetivo identificar o nível de saúde e desempenho motor dos alunos, eles são ranqueados de acordo com os resultados. Esses testes são fundamentados no manual de teste e avaliação do Projeto Esporte Brasil PROESP 2016 (MATO GROSSO, 2017).

Nos testes para avaliação do nível de saúde são verificados e analisados os índices de Massa Corporal (IMC), Razão Cintura Estatura (RCE), aptidão cardiorrespiratória, flexibilidade, resistência muscular localizada (abdominal) (GAYA; GAYA, 2016).

Nos testes de aptidão física para avaliar o desempenho motor são avaliados os índices de: força explosiva dos membros superiores, força explosiva dos membros inferiores, teste de agilidade, teste de velocidade, aptidão cardiorrespiratória (GAYA; GAYA, 2016).

Após a seleção, os alunos passam por uma vivência esportiva. Nesse período, eles visitam todas as modalidades para vivenciar e ver se têm aptidão para a modalidade. Ao final desse processo, os professores fazem uma reunião e alocam todos os alunos em suas modalidades (EEGJF, 2019).

Para ser professor de Prática Esportiva na escola, o professor deve participar do Processo Seletivo Simplificado (PSS) da Secretaria de Educação do Estado de Mato Grosso e, depois, participar de uma banca, em que cada candidato apresenta seu plano de aula de acordo com a modalidade para qual se candidata (MATO GROSSO, 2019).

Para concorrer à vaga, o professor deve ser habilitado em Educação Física com habilitação para Licenciatura e, também, apresentar o registro no Conselho de Educação Física, ou o CREF provisionado para atuar na modalidade (MATO GROSSO, 2019).

Os professores são contratados para um regime 40 horas semanais, dessas 20 são destinadas ao ensino da prática com os alunos, 10 horas são destinadas para planejamento da prática pedagógica e 10 horas para a produção científica (MATO GROSSO, 2019).

A proposta pedagógica da Escola propõe que a Base Comum se integre diretamente com a Prática Esportiva. Nessa perspectiva, todos os professores das áreas devem estabelecer alguma correlação da sua disciplina com a prática esportiva (EEGJF, 2019).

Quanto aos resultados da análise de como eram feitos os planejamentos dos oito docentes investigados, por meio das entrevistas, verificou-se que eles se guiam pelas habilidades de cada componente curricular embasado na BNCC, inclusive, os professores das modalidades esportivas destacam os conteúdos para cada ano que a escola oferece que, em 2019, foi do oitavo ano do Ensino Fundamental ao terceiro ano do Ensino Médio, articulando os conhecimentos dos componentes curriculares da BNCC, da parte Diversificada incluindo as modalidades esportivas adotadas.

Todos os docentes produzem planejamentos anuais e quinzenais, além do Guia Bimestral dos componentes curriculares tanto da BNCC tanto da parte diversificada, incluindo as Eletivas, contemplando as modalidades esportivas adotadas na escola. Os professores da prática esportiva fazem um planejamento mais na parte técnica e tática e a grande maioria das suas aulas são práticas e valorizam muito a participação dos alunos, como forma de proporcionar a sua autonomia e o seu protagonismo.

De um modo geral, a sondagem foi bastante citada como forma de preparar os planejamentos das aulas, contando com a participação dos alunos opinando sobre o que gostariam de aprender, porém foi ressaltado que somente com o aval do professor, quando fosse pertinente à necessidade de aprendizagem deles.

Observou-se nas falas dos participantes um enfoque interdisciplinar e transdisciplinar nos planejamentos, auxílio da internet, livros, além do uso de tecnologias digitais de informação e comunicação - TDIC. Foi também apontada a sondagem como forma de previsão para realizar o planejamento das aulas e a participação dos alunos opinando sobre o que gostariam de aprender, porém, é claro, somente com o aval do professor quando fosse pertinente à necessidade de aprendizagem deles.

É neste sentido que Torres Santomé (1994) afirma que a interdisciplinaridade é algo diferente, que reúne estudos complementares de diversos especialistas em um marco de estudo de âmbito mais coletivo. Ainda, defende que a interdisciplinaridade tem um grande poder estruturante, já que os conceitos, os marcos teóricos e os procedimentos como os que o alunado enfrenta se encontram organizados em torno de unidades mais globais, as estruturas conceituais e metodológicas compartilhadas por várias disciplinas.

Para Nicolescu (2000), a transdisciplinaridade se sustenta em três princípios: níveis de realidade, complexidade e terceiro incluído. É compreendida como o que ocorre dentro, atravessa e vai além das disciplinas científicas. Esses elementos indicam que a ciência não é algo pronto, inquestionável. Apesar disso, ainda ocorrem hermetismos nas áreas que compõem o conhecimento científico e a visão de um único caminho, para conhecimento da totalidade do real.

Além dos planejamentos dos professores, também foram investigadas como são trabalhadas as metodologias na escola. Sobre isso foi confirmado, em todas as entrevistas, o uso de múltiplas metodologias postas em prática articulando os 
saberes dos componentes curriculares da BNCC, da parte Diversificada e das modalidades esportivas.

Foram apontadas aulas teóricas, práticas, realização de experimentos científicos, uso de tecnologias de comunicação e informação, aulas de campo e o uso constante da interdisciplinaridade e da transdisciplinaridade.

O emprego de metodologias ativas foi o diferencial observado nas falas dos professores nas entrevistas, que por diversas vezes mencionaram o protagonismo dos alunos, assim como a sua autonomia para a realização de tudo o que a escola produziu no ano letivo de 2019.

Dessa maneira, foram analisadas as falas dos participantes acerca da metodologia utilizada nos planejamentos das aulas dos docentes investigados. Foi verificado que todos os oito docentes entrevistados fizeram o uso de diversas metodologias para aperfeiçoar a sua prática pedagógica e ampliar a aprendizagem dos estudantes, articulando os saberes dos componentes curriculares da BNCC e da parte Diversificada, incluindo as modalidades esportivas. Entre as metodologias utilizadas estão aulas teóricas, práticas, extraclasse, realização de experimentos científicos, uso de tecnologias de comunicação e informação, aulas de campo e o uso constante da interdisciplinaridade e de transdisciplinaridade.

O diferencial constatado, nas falas dos docentes, foi o emprego de metodologias ativas exemplificadas como estudos de caso, sala de aula invertida e dinâmicas. Vale ressaltar que, além do emprego dessa diversidade de metodologias, nas aulas de todos os componentes curriculares e também nas modalidades esportivas, foi muito utilizada, de forma interdisciplinar e transdisciplinar, nas Eletivas que aconteceram no primeiro e segundo semestres de 2019.

É importante dizer que a escola foi contemplada no modelo de ensino Escola Plena somente em 2019, sendo assim o seu primeiro ano trabalhado com esse novo modelo. Sendo assim, o emprego de mais metodologias sempre foi posto visando o aprendizado dos educandos, já que isso contribui como algo de suma importância para assegurar a sua formação integral.

\section{Conclusão}

Considerando que a temática abordada é de impacto social e acadêmico, pois teve como proposta apresentar a escola Plena, que é um modelo de Ensino Integral no Estado de Mato Grosso e, também, as suas estratégias pedagógicas inovadoras. Foi demonstrada a boa qualidade do ensino e aprendizagem dos alunos, que discutiu sobre a formação e os saberes dos professores, que trabalham em uma escola de tempo integral articulando conhecimentos da Base Nacional Comum Curricular com as modalidades esportivas resultando na educação integral.

Verificou-se e ficou nítido que este modelo de ensino exige muita dedicação e empenho por se tratar de um contexto, em que o aluno passa boa parte do seu dia na escola e os professores também. Nesse processo, a busca do docente foi incentivar, colaborar e ampliar os saberes destes estudantes para a construção do seu projeto de vida. Portanto, foi demonstrado nesta pesquisa que o referido modelo de ensino, bem como as estratégias pedagógicas contribuíram para a qualidade na educação e para formação integral do aluno, visto que o índice do IDEB de 2019 do Ensino Médio da escola alcançou 4,8, sendo o maior índice entre as Escolas Estaduais de Cuiabá e o sexto lugar em nível estadual entre as escolas da rede estadual. Isso demonstrou e provou que o fazer docente da escola investigada e o trabalho da gestão pedagógica escolar está no caminho certo, solidamente, para seguir colaborando para o sucesso da vida acadêmica de seus estudantes.

\section{Referências}

BARDIN, L. Análise de conteúdo. São Paulo: 70, 2016.

BAUER, M.W. Análise de conteúdo clássica: uma revisão. In: BAUER, M.W; GASKELL, G.(org.). Pesquisa qualitativa com texto, imagem e som: um manual prático. Petrópolis: Vozes, 2003. p.189-217.

CHIZZOTTI, A. A pesquisa qualitativa em ciências humanas e sociais: evolução e desafios. Rev. Port. Educ., v.16 n.2, 2003.

EEGJF - Escola Estadual Governador José Fragelli. Proposta pedagógica da Escola. Secretaria de Educação do Estado de Mato Grosso. Cuiabá: SEDUC, 2019.

GAYA, A.; GAYA, A.R. Projeto esporte Brasil: manual de testes e avaliação. Porto Alegre: UFRGS, 2016.

GIMENO SACRISTÁN, J. Poderes instáveis em educação. Porto Alegre: Artmed, 1999.

GONÇALVES, A.S. Reflexões sobre educação integral e escola de tempo integral. Cad. Cenpec, n.2, p. 129-135, 2006.

ICE - Instituto de Corresponsabilidade pela Educação. Introdução às bases teóricas e metodológicas do modelo Escola da Escolha. 2015.

MATO GROSSO. Lei $n^{\circ}$ 10.622, de 24 de outubro de 2017. Institui o Projeto Escola Plena, vinculado ao programa PróEscolas, no âmbito do Estado de Mato Grosso, 2017.

MATO GROSSO. Orientativo Pedagógico das Escolas de Educação em Tempo Integral Vocacionadas ao Esporte/2018. Cuiabá: Secretaria de Estado de Educação, Esporte e Lazer, 2018.

MATO GROSSO. Projeto Pedagógico de Educação em Tempo Integral. Cuiabá: Secretaria de Estado de Educação, 2019.

MINAYO, M.C.S; GOMES, R; DESLANDES, S.F. Pesquisa social: teoria, método e criatividade. Petrópolis: Vozes, 2018.

NICOLESCU, B. O manifesto da transdisciplinaridade. São Paulo: TRIOM, 2000.

TORRES SANTOMÉ, J. Globalización e interdisciplinariedad: el curriculum integrado. Madrid: Morata, 1994.

XAVIER, M. L. M. F. Educação Integral nas diretrizes curriculares nacionais e a exigência de um novo ordenamento curricular. Rev. Traj. Mult., v.3, n.7 2012. 